Int. J. Electrochem. Sci., 12 (2017) 10279 - 10290

\title{
Effect of Flow Rate on the Corrosion Behavior of N80 Steel in Simulated Oil Field Environment Containing $\mathrm{CO}_{2}$ and $\mathrm{HAc}$
}

\author{
Qingwei Niu ${ }^{1}$, Zili Li $^{1 *}$, Gan Cui ${ }^{1}$, Bingying Wang ${ }^{2}$ \\ ${ }^{1}$ College of Pipeline and Civil Engineering, China university of petroleum (East China), Qingdao, \\ China, 266580 \\ ${ }^{2}$ College of Mechanical and Electronic Engineering, China university of petroleum (East China), \\ Qingdao, China, 266580 \\ *E-mail: zilimenhuzu@163.com
}

doi: $10.20964 / 2017.11 .23$

Received: 15 July 2017 / Accepted: 4 September 2017 / Published: 12 October 2017

In most oil and gas fields, $\mathrm{CO}_{2}$ corrosion has become a significant problem plaguing the development of the oil industry. The usage of Acetic acid (HAc) as a common material in oil extraction increases the complexity of $\mathrm{CO}_{2}$ corrosion process. Among the many factors affecting the oil casing corrosion, the flow rate plays a decisive role. Therefore, in this work Wuhan Koster CS310 Electrochemical Station was used to measure the dynamic potential polarization curves and perform electrochemical impedance spectroscopy (EIS) at different concentrations of HAc and flow rates. Subsequently, the polarization curves were fitted to obtain the polarization characteristics, and corresponding equivalent circuits were chosen to fit the experimental EIS data. In the end, the corrosion behavior and corrosion mechanism of N80 steel were discussed based on corrosion electrochemical theory. It is concluded that the presence of HAc increases the self-corrosion potential $E_{c o r r}$ and self-corrosion current density $I_{\text {corr }}$ of N80 steel in saturated $\mathrm{CO}_{2}$ solution, promotes the anodic and cathodic reaction speed, and reduces the thickness and the protective effect of the corrosion product film. Furthermore, it is observed that the flow rate increases the corrosion current density of N80 steel, increases the electric double layer capacitance CPE, reduces the charge transfer resistance $R_{t}$, and eventually accelerates the corrosion rate of steel.

Keywords: $\mathrm{HAc}$; $\mathrm{CO}_{2}$; Flow rate; Corrosion behavior

\section{$\underline{\text { FULL TEXT }}$}

(C) 2017 The Authors. Published by ESG (www.electrochemsci.org). This article is an open access article distributed under the terms and conditions of the Creative Commons Attribution license (http://creativecommons.org/licenses/by/4.0/). 